\title{
Wetting properties of titanium oxides, oxynitrides and nitrides obtained by DC and pulsed magnetron sputtering and cathodic arc evaporation
}

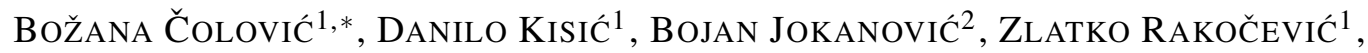 \\ Ilija Nasov ${ }^{3}$, AnKa Trajkovska PetKoska $^{4}$, Vukoman Jokanović ${ }^{1,5}$ \\ ${ }^{1}$ Vinča Institute of Nuclear Sciences, University of Belgrade, Mike Petrovića Alasa 12-14, 11001 Belgrade, Serbia \\ ${ }^{2}$ GL group, Werner-von-Siemens-Straße, 86405 Metingen, Germany \\ ${ }^{3}$ Plasma Doo, 29 November 66/9, 1000 Skopje, R. Macedonia \\ ${ }^{4}$ University St. Kliment Ohridski, Faculty of Technology and Technical Sciences, Titogradska 42, 1400 Veles, R. Macedonia \\ ${ }^{5}$ Albos doo, Orahovačka 19, 11000 Belgrade, Serbia
}

\begin{abstract}
Thin films of titanium oxides, titanium oxynitrides and titanium nitrides were deposited on glass substrates by the methods of direct current (DC) and pulsed magnetron sputtering and cathodic arc evaporation. Phase analysis of the deposited films by X-ray diffraction (XRD) and Fourier-transform infrared spectroscopy (FT-IR) showed the presence of phases with various Ti oxidative states, which indicated a high concentration of oxygen vacancies. The films morphology was investigated by scanning electron microscopy (SEM). Investigations of the films wettability, either with water or ethylene glycol, showed that it depends directly on the concentration of oxygen vacancies. The wettability mechanism was particularly discussed.
\end{abstract}

Keywords: wettability; titanium oxide; titanium nitride; magnetron sputtering; arc evaporation

\section{Introduction}

Self-cleaning coatings may be designed as hydrophobic and/or hydrophilic thin films since both of them clean the surfaces by their specific behavior towards water $[1,2]$. The hydrophobic film surfaces influence sliding of water droplets over them, carrying the dirt away, while hydrophilic films cause water to form "sheets", removing the dirt from the surface [2]. The base of self-cleaning phenomena is inspired by nature of hydrophobic/superhydrophobic or hydrophilic/super-hydrophilic selfcleaning [3]. The solid surface is considered as hydrophobic, for the contact angle (CA) with water higher than $90^{\circ}$ while for CA lower than $90^{\circ}$ the surface is considered as hydrophilic. If the $\mathrm{CA}$ is higher than $150^{\circ}$ the surface is referred as an ultrahydrophobic or super-hydrophobic, while if it is

*E-mail: bozana@vinca.rs close to $0^{\circ}$ (water completely wets the surface) the surface is judged as super-hydrophilic [1-3].

According to Cassie-Baxter model [4], during the heterogeneous wetting state (in which water in the surface cavities entraps air), the interface between liquid and solid tends to minimum, while the interface between water and air tends to maximum, influencing the formation of spherical droplets with low hysteresis, which can be additionally reduced by increasing the roughness and contact angle. The surface roughness can be controlled by nanoparticles with uniform size. Nevertheless, all methods used for deposition of thin films with low surface energy and controlled morphology on nano- and micro-scales, assume either roughening of low surface energy materials or modification of rough surface with low surface energy materials $[5,6]$.

The tailoring of materials wettability has been the topic of numerous experimental and theoretical investigations [7]. The super-hydrophobicity is mainly influenced by specially textured topography 
of the surface and the presence of a low energy coating material [8]. This property can be used in numerous applications, such as self-cleaning, anticorrosion coatings and biomaterials [1, 6]. Beside the known advantages of hydrophobic surfaces in diverse applications, recent focus in investigations is also dedicated to hydrophilic surfaces, which are suitable for water purification, in paint industry and for various kinds of medical implants [1,9]. The wettability of such surfaces is very high, and the water CA tends to be $0^{\circ}$. Besides, the maximum adsorption of proteins and cell adhesion and growth can be noticed on moderate hydrophilic surfaces having a water $\mathrm{CA}$ around $60^{\circ}$ [10].

Recent investigation shows that nano-titanium oxide, oxynitride and nitride films with tunable wettability for both water and non-aqueous solvents may have a very high impact on potential applications of these materials in medicine and food industry [11-13]. As it is known, titanium oxides and nitrides with low roughness, like these obtained in the sputtering process described in this paper, have low friction that is suitable for long-term fluid flow, during their exposure to certain media [1416]. Additionally, it induces an increase in heat exchange efficiency and the nonspecific adsorption of proteins, cells, thrombus, osteoarthritis, and so on. Such modified surface offers extended opportunities of applications, mainly as antimicrobial and self-cleaning coatings in the food technology and medicine applications [17]. Also they can be applied in the implantology, particularly for surface modification of various implants on the base of titanium, its alloys or other metal materials, like hip and knee prosthesis, implants for heart valves or venous and urinary tract catheters.

In this paper, titanium oxide, oxynitride and nitride films were deposited onto glass substrate by three different techniques, DC and pulsed magnetron sputtering and cathodic arc evaporation [18, 19]. Differences in wettability of titanium oxide films were investigated from the standpoint of the technique used and an additional thermal treatment, as well as differences in wettability of titanium oxide, oxynitride and nitride films obtained by cathodic arc evaporation.

\section{Experimental}

Microscopic glass slides $(7.5 \mathrm{~mm} \times 2.5 \mathrm{~mm} \times 1 \mathrm{~mm})$ were used as substrates for deposition of all films. Prior to deposition, the substrates were ultrasonically cleaned in propanol, rinsed with deionized water, well dried and then cleaned by etching in $\mathrm{O}_{2}$ atmosphere under a pressure of $2000 \mathrm{~Pa}$ and cathode potential of $2000 \mathrm{~V}$. The current was dependent on the sample surface and was between $1 \mathrm{~A}$ and $10 \mathrm{~A}$. The process lasted for $\sim 8 \mathrm{~min}$.

The titanium oxide (Ti-O) thin films were deposited on the substrate using a VU 1100 DC magnetron sputtering (DCMS) system. The samples were mounted on a holder at the distance $150 \mathrm{~mm}$ from the titanium target (purity of $99.999 \%$ ) with dimensions of $120 \mathrm{~mm} \times 1440 \mathrm{~mm} \times 10 \mathrm{~mm}$. Before introduction of sputtering gas, the vacuum of the chamber was evacuated to reach $0.01 \mathrm{~Pa}$. First, the flow of gas Ar (purity $99.999 \%$, pressure $10^{-4} \mathrm{~Pa}$ ) was introduced to the chamber and the potential was increased from $0 \mathrm{~V}$ to $400 \mathrm{~V}$ (while the current was increased from $0 \mathrm{~A}$ to $20 \mathrm{~A}$ ), to start the deposition process of Ti. The pressure in the chamber was $0.17 \mathrm{~Pa}$ and the deposition time for pure Ti was $1 \mathrm{~min}$. In the meantime, $\mathrm{O}_{2}$ flowed into the chamber (purity $99.999 \%$, pressure $500 \mathrm{~Pa}$ ), while the potential changed from $400 \mathrm{~V}$ to $430 \mathrm{~V}$ (the current was $16 \mathrm{~A})$. The deposition rate was about $4 \mathrm{~nm} / \mathrm{min}$ and the deposition time was 10 minutes. Two samples were made and one of them was additionally thermally treated at $400{ }^{\circ} \mathrm{C}$.

The Ti-O thin films were also deposited onto the substrate by pulsed magnetron sputtering (PMS) with a gun perpendicular to the target surface. The samples were mounted on a holder at the distance $150 \mathrm{~mm}$ from the titanium target (purity of $99.999 \%$ ) with dimensions of $120 \mathrm{~mm} \times 1440 \mathrm{~mm} \times 10 \mathrm{~mm}$. When the vacuum reached $0.01 \mathrm{~Pa}$, the deposition process started by introduction of Ar flow into the chamber (purity $99.999 \%, 60 \mathrm{~Pa}$ ). The potential in the chamber increased from $0 \mathrm{~V}$ to $500 \mathrm{~V}$ and current from $0 \mathrm{~A}$ to $10 \mathrm{~A}$. The pressure in the chamber during the deposition process was $0.17 \mathrm{~Pa}$, while the deposition time was $1 \mathrm{~min}$ for pure Ti. After Ti deposition, 
$\mathrm{O}_{2}$ gas was introduced into the chamber (purity $99.999 \%, 500 \mathrm{~Pa}$ ) and the potential changed from $500 \mathrm{~V}$ to $530 \mathrm{~V}$ (current $16 \mathrm{~A}$ ), while the pressure was $0.18 \mathrm{~Pa}$. The deposition rates were $8 \mathrm{~nm} / \mathrm{min}$ to $10 \mathrm{~nm} / \mathrm{min}$ and the deposition time was $10 \mathrm{~min}$ utes. Two samples were made and one of them was additionally thermally treated at $400{ }^{\circ} \mathrm{C}$.

Thin films of titanium oxides (Ti-O), titanium oxynitrides (Ti-O-N) and titanium nitrides (Ti-N) were deposited on the substrates by cathodic arc evaporation (CAE). The substrates were mounted perpendicular to the direction of the plasma beam at $\sim 150 \mathrm{~mm}$ distance from the target. Titanium (purity $99.999 \%$ ) with a diameter of $60 \mathrm{~mm}$ and height of $1780 \mathrm{~mm}$ was used as a target. The substrate was placed on a turntable holder and the trigger voltage of pulsed arc was kept at $-10 \mathrm{kV}$ during the deposition. When the vacuum in the chamber reached $0.01 \mathrm{~Pa}$, the deposition process started with a flow of $\operatorname{Ar}(40 \mathrm{~Pa})$. The samples rotated during this process and the current was 160 A to $180 \mathrm{~A}$. After $30 \mathrm{~s}$ of the deposition of pure Ti, $\mathrm{O}_{2}$ (purity $99.999 \%, 2000 \mathrm{~Pa}$ ) was gradually introduced to the reaction chamber under controlled partial pressure in the range $0.17 \mathrm{~Pa}$, and Ar flow was stopped. The Ti-N films were deposited at a $\mathrm{N}_{2}$ partial pressure of $0.1 \mathrm{~Pa}$, while for the deposition of Ti-O-N a mixture of the $\mathrm{O}_{2}$ and $\mathrm{N}_{2}$ (ratio 1:1) was used, at the total gas pressure of $0.002 \mathrm{~Pa}$. In the case of all films, the deposition rate was $10 \mathrm{~nm} / \mathrm{min}$, and the deposition time was $5 \mathrm{~min}$.

Phase composition of the samples was analyzed by XRD (Philips PW 1051 powder diffractometer using Ni-filtered $\mathrm{CuK} \alpha$ radiation) and FT-IR (Nicolet IS 50 FT-IR spectrometer). Microstructure of the samples was analyzed by SEM (SEM JEOL 5300). The wettability measurements were performed on a homemade device equipped with CCD detector. During the measurements, blue LED lamp (Kingbright Electronic Co., Ltd.) was used for the samples lightening. All samples were measured in the same conditions and each sample was evaluated by 5 drops of polar liquid - deionized water, and by 5 drops of a non-polar liquid - ethylene glycol.

\section{Results and discussion}

\subsection{XRD analysis}

XRD spectra of Ti-O films obtained by DCMS method are shown in Fig. 1 (film appearances are shown in Part A, Fig. 9, below). The sample obtained by DC magnetron sputtering shows the planes characteristic of TiO: $\left(\begin{array}{lll}0 & 3 & 1\end{array}\right)$ and $\left(\begin{array}{lll}-2 & 1 & 1\end{array}\right)$ at $37.24^{\circ}$ and $37.43^{\circ}$, respectively [20], while the sample obtained by DC magnetron sputtering and additionally thermally treated shows the planes characteristic of anatase: (llll 0101$),\left(\begin{array}{lll}0 & 0 & 4\end{array}\right)$ and (1 112 ) at $25.27^{\circ}, 37.72^{\circ}$ and $38.58^{\circ}[21,22]$, respectively, as well as planes characteristic of rutile:

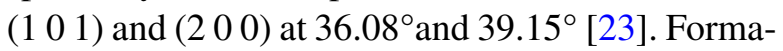
tion of the anatase and rutile phases in the second sample indicates that the recrystallization process took place in the system during the additional thermal treatment.

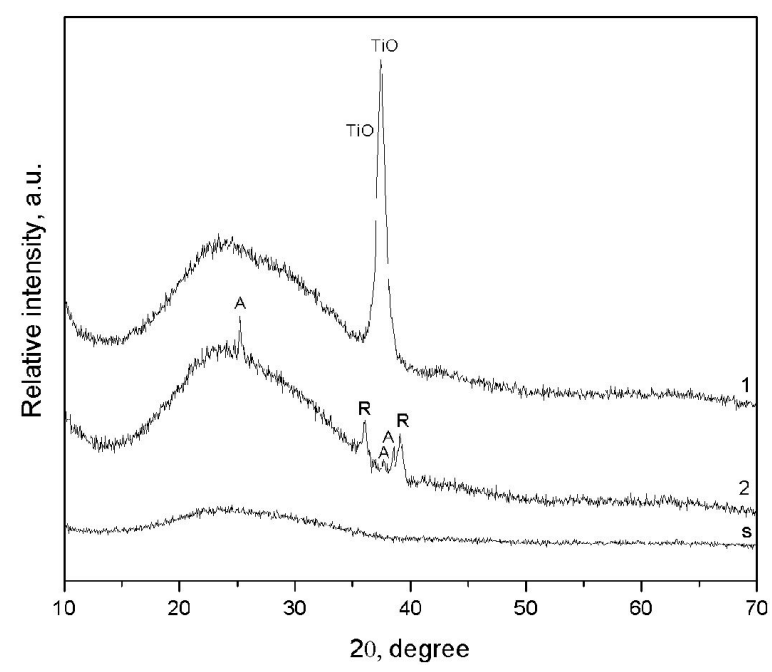

Fig. 1. XRD patterns of Ti-O films obtained by DCMS ( 1 - sample as-deposited, 2 - sample thermally treated at $400{ }^{\circ} \mathrm{C}, \mathrm{s}$ - substrate; A - anatase, $\mathrm{R}$ rutile).

As it is obvious from Fig. 1, the shape and maximum of the broad peaks in the $2 \theta$ range between $15^{\circ}$ and $30^{\circ}$ are more pronounced for both samples than those for amorphous $\mathrm{SiO}_{2}$ on the substrate, indicating that amorphous phase of Ti-O is prevailing over titanium phase. Crystallite sizes calculated using Scherer equation are in the range of $7 \mathrm{~nm}$ to $25 \mathrm{~nm}$. 
XRD spectra of Ti-O films obtained by PMS are shown in Fig. 2 (film appearances are shown in Part A, Fig. 10). The sample obtained by PMS deposition shows the planes characteristic of $\mathrm{TiO}$ : ( $\left.\begin{array}{lll}0 & 1 & 1\end{array}\right),\left(\begin{array}{lll}0 & 3 & 1\end{array}\right)$ and $\left(\begin{array}{lll}2 & 2 & 0\end{array}\right)$ at $24.61^{\circ}, 36.38^{\circ}$ and $43.08^{\circ}$, respectively. Sample obtained by PMS deposition and additional thermal treatment shows characteristic planes of anatase: (llll $\left.\begin{array}{lll}1 & 0 & 1\end{array}\right),\left(\begin{array}{lll}0 & 0 & 4\end{array}\right)$, (2 $\left.\begin{array}{lll}2 & 0\end{array}\right)$ and $\left(\begin{array}{lll}2 & 1 & 1\end{array}\right)$ at $25.27^{\circ}, 38.19^{\circ}, 48.05^{\circ}$ and $55.24^{\circ}$, respectively, as well as planes characteristic of rutile: (1 110$),\left(\begin{array}{lll}1 & 0 & 1\end{array}\right),\left(\begin{array}{lll}1 & 1 & 1\end{array}\right)$ and $\left(\begin{array}{lll}2 & 1 & 1\end{array}\right)$ at $27.28^{\circ}, 35.99^{\circ}, 41.16^{\circ}$ and $54.28^{\circ}$, respectively. Formation of the anatase and rutile phases in the second sample confirms that the recrystallization process took place in the system. TiO phase $\left(\begin{array}{lll}1 & 2 & 3\end{array}\right)$ at $62.61^{\circ}$ is also present in small quantity.

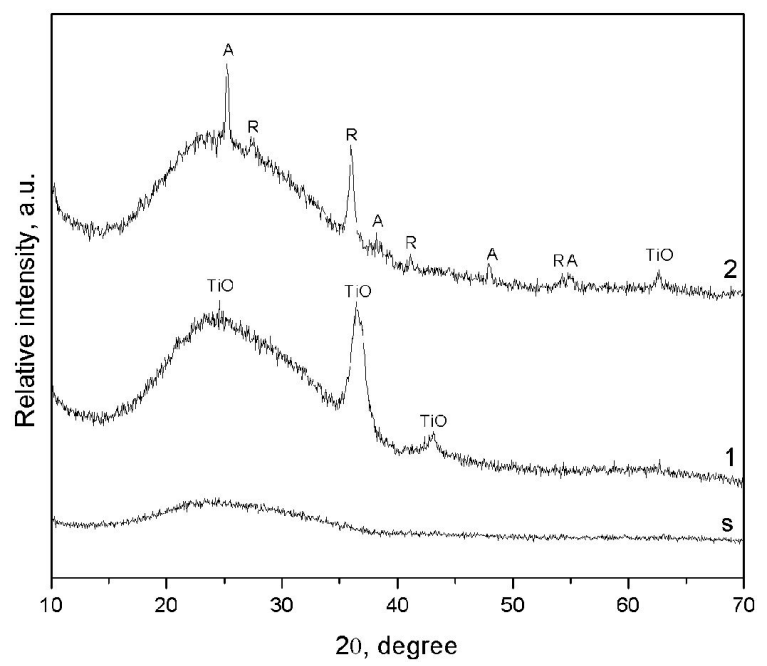

Fig. 2. XRD patterns of Ti-O films obtained by PMS (s - substrate, 1 - sample as-deposited, 2 - sample thermally treated at $400{ }^{\circ} \mathrm{C} ; \mathrm{A}$ - anatase, $\mathrm{R}-$ rutile).

XRD patterns of the $\mathrm{Ti}-\mathrm{O}$, Ti-O-N and $\mathrm{Ti}-\mathrm{N}$ films deposited on the glass substrates by CAE are shown in Fig. 3 (film appearances are shown in Part A, Fig. 11). All XRD patterns show the broad and intensive peak at $23.84^{\circ}$ corresponding to the glass substrate, whose XRD pattern is also given. The XRD pattern of the Ti-O film does not show presence of any other peak.

On the XRD pattern of Ti-O-N film (Fig. 3), the peak corresponding to titanium nitride (TiN) is found at $36.90^{\circ}$ (plane $\left(\begin{array}{lll}1 & 1 & 1\end{array}\right)$ ), while the peak corresponding to titanium oxide-hongquiite $\left(\mathrm{Ti}_{0.895} \mathrm{O}_{0.77}\right.$, marked as $\mathrm{TiO}_{\mathrm{h}}$ in Fig. 3) is identified at $37.68^{\circ}$ (plane $\left(\begin{array}{lll}1 & 1 & 1\end{array}\right)$ ) $[24,25]$.

The XRD pattern of Ti-N film (Fig. 3) shows peaks at $36.76^{\circ}$ and $78.02^{\circ}$ corresponding to titanium nitride, $\mathrm{Ti}_{2} \mathrm{~N}$ (planes (lll) $\left.1 \begin{array}{ll}1 & 1\end{array}\right)$ and $\left(\begin{array}{lll}2 & 2 & 4\end{array}\right)$, respectively) and TiN (plane (2 22 2) at $78.02^{\circ}$ ).

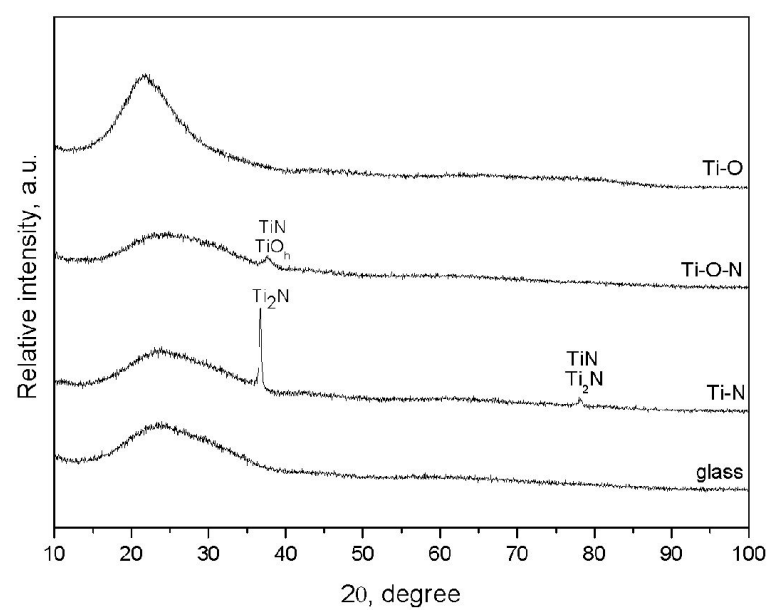

Fig. 3. XRD patterns of Ti-O, Ti-O-N and Ti-N films obtained by CAE.

Beside crystal phases, amorphous phase is probably present in all samples (the differences between the appearance of the peak belonging to the glass substrate and the substrate coated with $\mathrm{Ti}-\mathrm{O} / \mathrm{Ti}-\mathrm{O}-\mathrm{N}$ films can be noticed, in greater or lesser degree.

\subsection{FT-IR analysis}

FT-IR spectra of Ti-O films obtained by DCMS and PMS are shown in Fig. 4. The bands at about $910 \mathrm{~cm}^{-1}$ can be assigned to vibrations of $\mathrm{TiO}_{6}$ octahedron, related to Ti-O stretching bonds and the bands around $840 \mathrm{~cm}^{-1}$ to $850 \mathrm{~cm}^{-1}$ correspond to the $\mathrm{O}-\mathrm{O}$ stretching vibrations inside TiOOH [23]. The bands in wave number region of $745 \mathrm{~cm}^{-1}$ to $735 \mathrm{~cm}^{-1}$ belong to Ti-O and $\mathrm{Ti}-\mathrm{O}-\mathrm{Ti}$ stretching vibrations of anatase. The bands at $497 \mathrm{~cm}^{-1}$ to $460 \mathrm{~cm}^{-1}$ may correspond to the TP phonon frequency of $\mathrm{TiO}_{2}$ in the rutile phase, the bands at $460 \mathrm{~cm}^{-1}$ to $450 \mathrm{~cm}^{-1}$ can be assigned to vibrations of $\mathrm{TiO}_{6}$ octahedron, 
related to Ti-O stretching bonds, while the bands at $434 \mathrm{~cm}^{-1}$ to $406 \mathrm{~cm}^{-1}$ correspond to the TP phonon frequency of nanocrystaline $\mathrm{TiO}_{2}$ phase anatase or rutile phase [26-28].
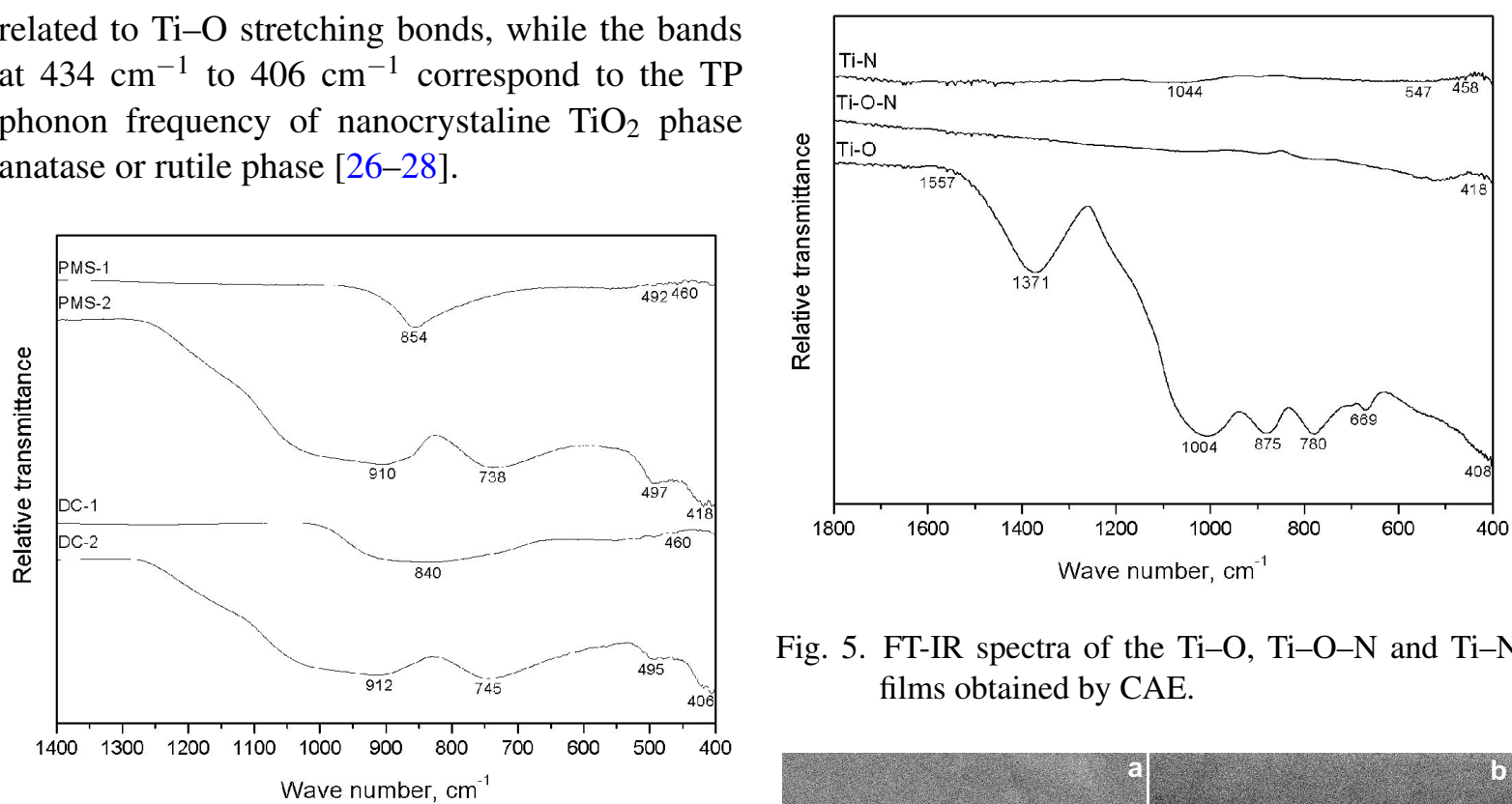

Fig. 5. FT-IR spectra of the Ti-O, Ti-O-N and Ti-N films obtained by CAE.

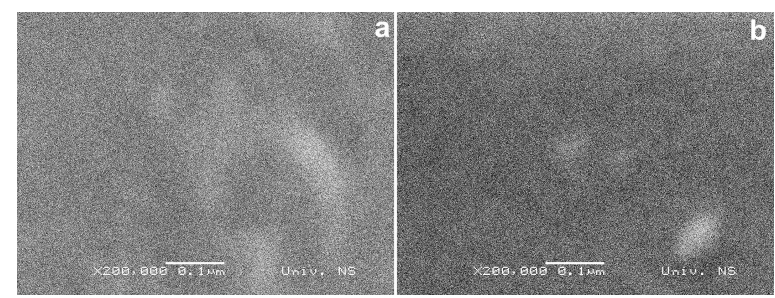

Fig. 6. SEM: Typical appearance of Ti-O films obtained by DCMS: (a) sample as-deposited, (b) sample thermally treated at $400{ }^{\circ} \mathrm{C}$.

films deposited by CAE are shown in Fig. 5. The bands between $1371 \mathrm{~cm}^{-1}$ and $1557 \mathrm{~cm}^{-1}$ can be assigned to vibration of $\mathrm{CO}^{2-}$ inside the carbonate impurities. The bands from $408 \mathrm{~cm}^{-1}$ to $1004 \mathrm{~cm}^{-1}$ can be assigned to Ti-O-Ti stretching vibrations and vibrations on the level of Ti-O bond. The band at $1044 \mathrm{~cm}^{-1}$ can be attributed to Ti-N stretching vibrations, while vibrations at $547 \mathrm{~cm}^{-1}$ can be attributed to Ti-N stretching modes and $\mathrm{Ti}-\mathrm{O}$ vibrations in titanium oxides. The band at $458 \mathrm{~cm}^{-1}$ can be attributed to the Ti-O-Ti vibrations and to the formation of N-Ti-N bonds, and the band at $418 \mathrm{~cm}^{-1}$ can be assigned to the formation of N-Ti-N bonds [29].

\subsection{The morphology of the films}

SEM micrographs of Ti-O films obtained by DCMS show almost flat surface (Fig. 6). Slight unevenness of the film thickness is probably induced by the surface irregularities of the glass substrate.

SEM micrographs of Ti-O films obtained by PMS without additional thermal treatment (Fig. 7a)

show almost flat surface with barely visible surface features of the film, while the thermally treated film (Fig. 7b) exhibits some surface irregularities, in the range $45 \mathrm{~nm}$ to $90 \mathrm{~nm}$.

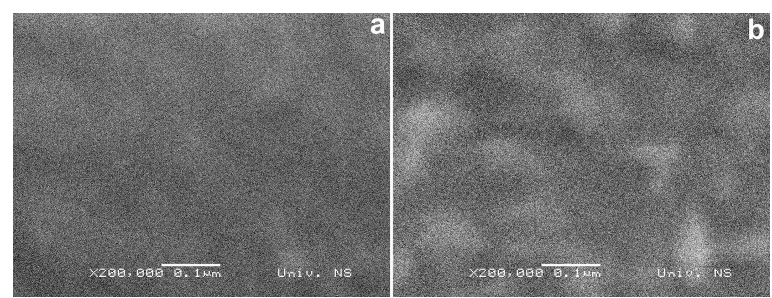

Fig. 7. SEM: Typical appearance of Ti-O films obtained by PMS for: (a) sample as-deposited, (b) sample thermally treated at $400{ }^{\circ} \mathrm{C}$.

The morphology of the films obtained by CAE (Fig. 8) depends on the film type (Ti-O, Ti-O-N or Ti-N). The morphology of Ti-O film is similar to Ti-O film obtained by previous methods, while 
the morphology of $\mathrm{Ti}-\mathrm{O}-\mathrm{N}$ and $\mathrm{Ti}-\mathrm{N}$ films is more expressive with similar features of $70 \mathrm{~nm}$ to $150 \mathrm{~nm}$ in size.

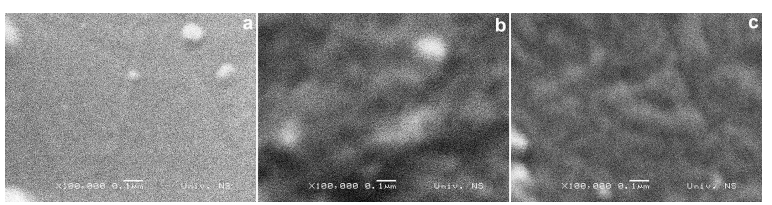

Fig. 8. SEM micrographs of the films obtained by CAE: (a) Ti-O, (b) Ti-O-N and (c) Ti-N.

\subsection{Wetting properties}

In general, it is believed that the hydrophilic properties of Ti-O film surface originate from water adsorption on oxygen vacancies created. Observing the data given in Table 1 (images are given in Part B) it is obvious that Ti-O films subjected to additional thermal treatment show significantly lower contact angles and better wettability (either with water or ethylene glycol). The polar part of adhesion energy for Ti-N film is particularly pronounced.

The most commonly accepted mechanism in studying hydrophobic and hydrophilic properties of thin films is surface hydroxylation of thin layers present on the surface of titanium oxides with holes located in the valence band, induced by the presence of easily moving oxygen vacancies (OV), in its surrounding [30]. Relatively small energy of electromagnetic wave of light to which the samples were exposed before and during contact angle measurements was sufficient to move the vacancies along their concentration gradient, from the deeper layers to the surface which was more saturated with oxygen. As a result, the oxygen diffused from the surface to the deeper layers. Such replacement of the OV along their gradient formed between adjacent layers induced random holes movement toward the surface, and their interaction with Ti-O bonds, influencing their breaking and change of the oxidative state from $\mathrm{Ti}^{4+}$ to $\mathrm{Ti}^{3+}$. Briefly, the OV approaching the surface replace the oxide ions, forming the bridges $\mathrm{Ti}^{3+}-\mathrm{OV}-\mathrm{Ti}^{3+}$ between two coordination unsaturated $\mathrm{Ti}^{3+}$ ions, consequently influencing the corresponding distortion of the coordination geometry of Ti ions. Therefore, due to adjacent OV, these Ti ions show tendency to form additional coordinative connections with surrounding ions, while the $\mathrm{OV}$ act as adsorption sites for water molecules [31]. Water molecules occupy the $\mathrm{OV}$ and produce chemisorbed $-\mathrm{OH}$ groups, which leads to an increase of the Van der Waals forces and the hydrogen-bonding interactions between the $\mathrm{H}_{2} \mathrm{O}$ and the $-\mathrm{OH}$, resulting finally in the enhancement of hydrophilic properties [32].

For Ti-O films which were additionally thermally treated, the gradient of OV is strongly pronounced, while it is not as large as for the films that were not thermally treated, inducing slower vacancy motion and less number of the bridges, such as $\mathrm{Ti}^{3+}-\mathrm{OV}-\mathrm{Ti}^{3+}$ bridges. This is why the contact angle decreases with the thermal treatment.

Therefore, it seems that the defect structure and very small band gap values obtained due to the presence of the phases with very low Ti oxidative states, are the most important for films behavior, regardless of whether they are on the base of titanium oxides or titanium nitrides. Therefore, the difference in wetting angles of $\mathrm{Ti}-\mathrm{O}$ and Ti-N films cannot be attributed to the different oxidative states of $\mathrm{Ti}\left(4+\right.$ in $\mathrm{TiO}_{2}$ and $3+$ in $\left.\mathrm{TiN}\right)$ only. The wetting phenomenon is more complex because Ti inside Ti-O and Ti-N samples can be found in lower oxidative states (about $2+$ in oxides and $1.5+$ in nitrides). Regardless of which film is observed, the concentration gradient of OV inside the film has a prevailing influence on the adsorption of $\mathrm{OH}$ groups from water and consequently, on the contact angle.

Similar effect has been observed in case of ethylene glycol. The value of its contact angle on the surfaces of oxides, oxynitrides and nitrides films is mainly influenced by the concentration gradient of $\mathrm{OV}$, showing frequently similar tendency to the increase/decrease as in the case of water.

Besides, the surface roughness may also influence the value of the water-contact angle, wherein rough surface gives a lower contact angle than a smooth one [32]. This influence was not so noticeable in our case, as it can be seen on the example of the films obtained by CAE (Fig. 8): contact angle of Ti-O-N film is similar to the contact angle 
Table 1. Surface energies and contact angles of the films wetted with water and ethylene glycol.

\begin{tabular}{|c|c|c|c|c|c|}
\hline \multirow[t]{2}{*}{$\begin{array}{l}\text { Method of } \\
\text { deposition }\end{array}$} & \multirow[t]{2}{*}{ Sample } & \multirow{2}{*}{$\begin{array}{l}\text { Contact } \\
\text { angle with } \\
\text { water }\left[{ }^{\circ}\right]\end{array}$} & \multirow{2}{*}{$\begin{array}{c}\text { Contact angle } \\
\text { with ethylene } \\
\text { glycol }\left[{ }^{\circ}\right]\end{array}$} & \multicolumn{2}{|c|}{ Surface energy $\left[\mathrm{mJ} / \mathrm{m}^{2}\right]$} \\
\hline & & & & Polar part & Nonpolar part \\
\hline \multirow{2}{*}{ DCMS } & Ti-O (as-deposited) & 83.6 & 56.7 & 12.8 & 16.0 \\
\hline & Ti-O (thermally treated) & 39.4 & 36.8 & 64.7 & 2.3 \\
\hline \multirow{2}{*}{ PMS } & Ti-O (as-deposited) & 87.1 & 60.8 & 8.3 & 18.5 \\
\hline & Ti-O (thermally treated) & 34.8 & 24.1 & 62.1 & 4.6 \\
\hline \multirow{3}{*}{ CAE } & Ti-O & 77.5 & 66.5 & 20.4 & 6.7 \\
\hline & $\mathrm{Ti}-\mathrm{O}-\mathrm{N}$ & 75.9 & 54.1 & 13.3 & 16.9 \\
\hline & Ti-N & 31.7 & 25.8 & 68.5 & 3.1 \\
\hline
\end{tabular}

of Ti-O and differs a lot from the contact angle of $\mathrm{Ti}-\mathrm{N}$, although the surface roughness of Ti-O-N and $\mathrm{Ti}-\mathrm{N}$ is similar, while Ti-O has almost flat surface.

\section{Part A: appearance of the deposited films}

Pieces of the glass substrates with deposited films were photographed in order to present different colors of the films (Fig. 9 to Fig. 11).

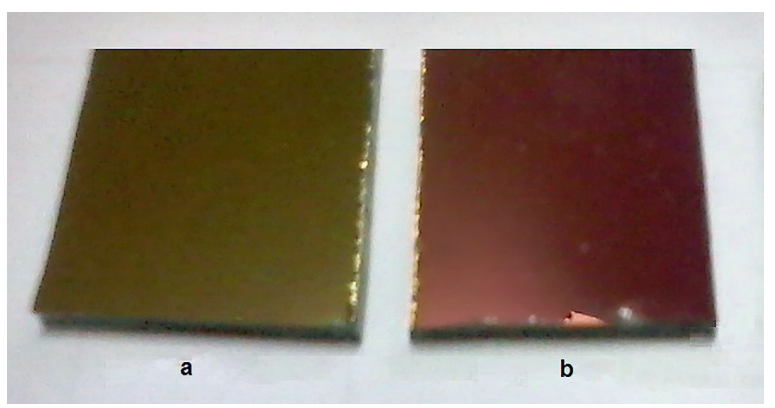

Fig. 9. Samples obtained by DCMS: (a) as-deposited, (b) thermally treated at $400{ }^{\circ} \mathrm{C}$.

\section{Part B: wetting angles of the obtained films}

Wetting angles with water and ethylene glycol were determined from the images given below using Drop Analysis software (Fig. 12 to Fig. 14).

\section{Conclusions}

Thin films based on titanium oxides, titanium oxynitrides and titanium nitrides, deposited

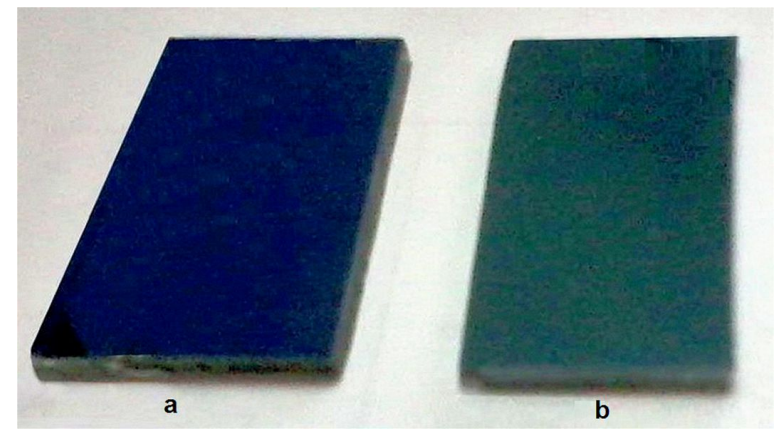

Fig. 10. Samples obtained by PMS: (a) as-deposited, (b) thermally treated at $400{ }^{\circ} \mathrm{C}$.

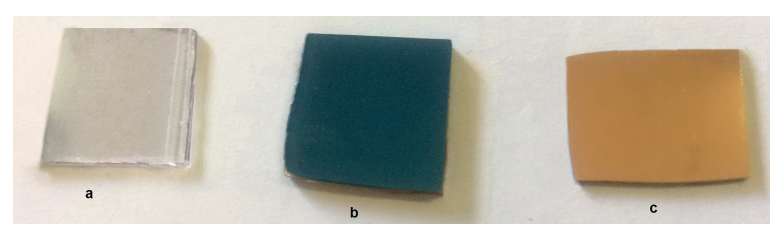

Fig. 11. Samples obtained by CAE: (a) Ti-O, (b) Ti-O-N, (c) Ti-N.

by methods of DC and pulse magnetron sputtering and cathodic arc evaporation onto glass substrates, were investigated. XRD and FT-IR analyses revealed the presence of phases with Ti oxidative states from $1.5+$ to $4+$, induced by enormous concentration of oxygen vacancies. Contact angle measurements showed that the differences in wettability of the samples obtained by different deposition techniques were relatively small. On the other hand, additional thermal treatment 


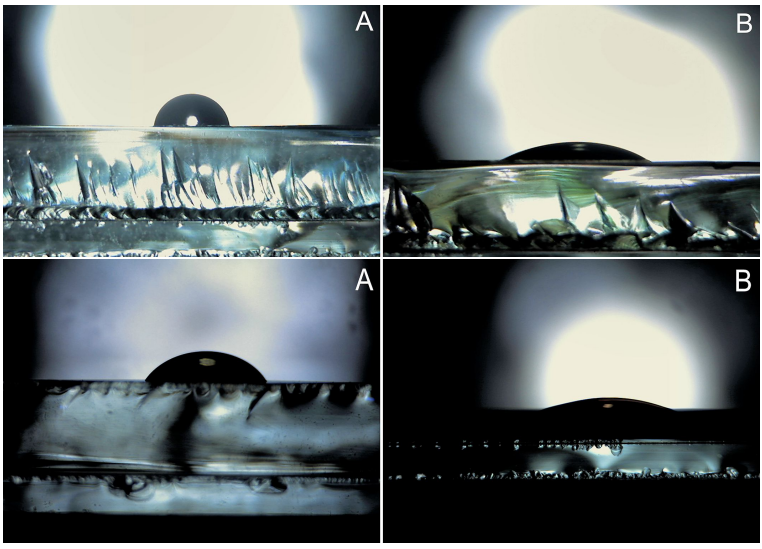

Fig. 12. Samples obtained by DCMS wetted by: (a) water, (b) ethylene glycol (A - as-deposited, B thermally treated at $400{ }^{\circ} \mathrm{C}$ ).

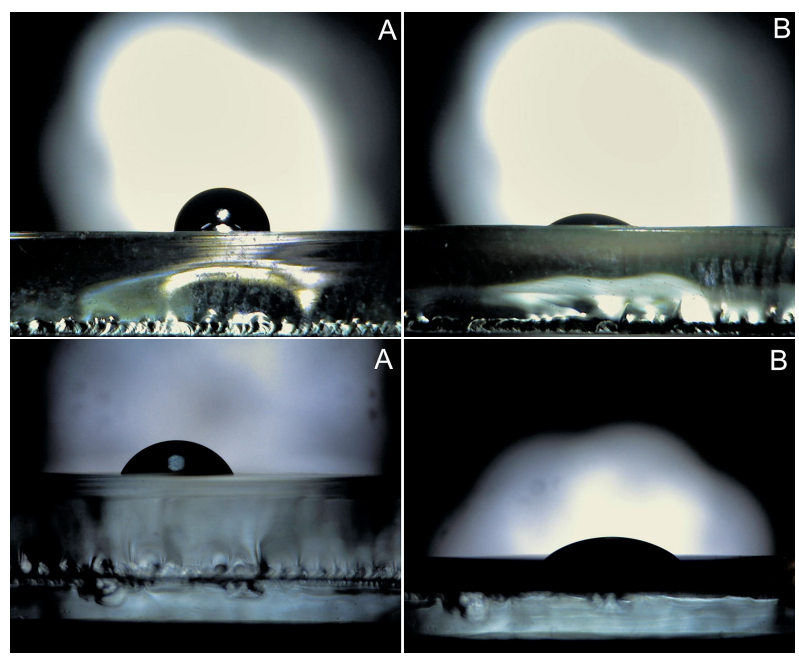

Fig. 13. Samples obtained by PMS wetted by: (a) water, (b) ethylene glycol (A - as-deposited, B thermally treated at $400{ }^{\circ} \mathrm{C}$ ).

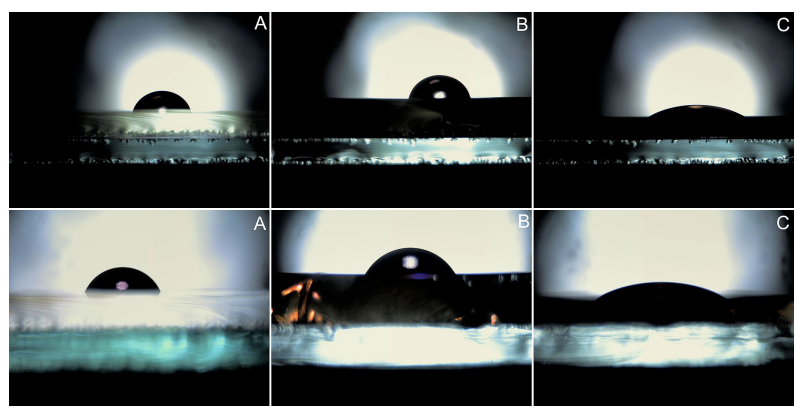

Fig. 14. Samples obtained by CAE wetted by: (a) water and (b) ethylene glycol (A - Ti-O, B - Ti-O$\mathrm{N}, \mathrm{C}-\mathrm{Ti}-\mathrm{N})$. significantly affected the wettability, since it depends on the concentration of oxygen vacancies on the film surface. The films wettability, either with water or ethylene glycol, influenced by corresponding gradient of oxygen vacancies was discussed in detail.

\section{Acknowledgements}

This study was supported by the Ministry of Education, Science and Technological Development of the Republic of Serbia (Project No. 172026).

\section{References}

[1] Parkin I.P., Palgrave R.G., J. Mater. Chem., 15 (2005), 1689.

[2] Ganesh V.A., Raut H.K., Nair A.S., RamakrISHNA S.A., J. Mater. Chem., 21 (2011), 16304.

[3] Ragesh P., Ganesh V.A., Nair S.V., Nair A.S., J. Mater. Chem., A2 (2014), 14773.

[4] Choi W., Tuteja A., Mabry J.M., Cohen R.E., MCKInley G.H., J. Colloid. Interf. Sci., 339 (2009), 208.

[5] Jokanović V., VilotiJević M., Jokanović B., Jenko M., AnŽEl I., Stamenković D., LaziC V., Rudolf R., Corr. Sci., 82 (2014), 180.

[6] Feng L., Li S., Li Y., Li H., Zhang L., Zhai J., Song Y., LiU B., JiAng L., ZHU D., Adv. Mater., 14 (2002), 1857.

[7] Balaur E., Macak J.M., Taveira L., Schmuki P., Electrochem. Commun., 7 (2005), 1066.

[8] NaKaJima A., NPG Asia Mater., 3 (2011), 49.

[9] Drelich J., Chibowski E., Meng D.D., TerpiLOWSKI K., Soft Mater., 7 (2011), 9804.

[10] XU L.C., Siedlecki C.A., Biomaterials, 28 (2007), 3273.

[11] Gittens R.A., Scheideler L., Rupp F., Hyzy S.H., Geis-Gerstorfer J., Schwartz Z., Boyan B.D., Acta Biomater., 10 (2014), 2907.

[12] Rawal S.K., Chawla A.K., Jayagantha R.N, Chandra R., J. Mater. Sci. Technol., 28(2012), 512.

[13] Karagkiozaki V., Logothetidis S., KalfagianNis N., Lousinian S., Giannoglou G., Nanomed. Nanotech. Biol. Med., 5 (2009), 64.

[14] Yeniyol S., BÖlÜKbaş N., BILIR A., ÇAKIR A.F., YENIYOL M., OZDEMIR T., ISRN Biomaterials, 2013 (2013), 783873.

[15] Jokanović V., Čolović B., Nenadović M., TraJKovska Petkoska A., Mitrić M., Jokanović B., NASOV I., Adv. Mater. Sci. Eng., 2016 (2016), 4565493.

[16] Ching H.A., Choudhury D., Nine M.J., AzUan N., Osman A., Sci. Technol. Adv. Mater., 15 (2014), 014402.

[17] Wojcieszak D., Mazur M., Kaczmarek D., Poniedzialek A., Osekowska M., Mater. Sci.Poland, 35 (2017), 421. 
[18] Kelly P.J., ARnell R.D., Vacuum, 56 (2000), 159.

[19] JokAnović V., Čolović B., TrajkovsKa Petkoska A., Mraković A., Jokanović B., Nenadović M., Ferrara M., Nasov I., Plasma Sci. Technol., 19 (2017), 125504.

[20] Watanabe D., Castles J.R., Jostsons A., Malin A.S., Acta Crystallogr., 23 (1967), 307.

[21] Legrand C., Delville J., C. R. Hebd. Seances Acad. Sci., 236 (1953), 944.

[22] Quirama A., Echavarría A.M., Meza J.M., Osorio J., BeJarano G., Vacuum, 146 (2017), 22.

[23] Sanches E., Lopez T., Gomez R., BoKhimi R., Morales A., Novaro O., J. Solid State Chem., 122 (1996), 309.

[24] Jiang C.C., Goto T., Hira T., J. Alloy. Compd., 190 (1993), 197.

[25] Straumanis M.E., Li H.W., Z. Anorg. Allg. Chem., 305 (1960), 143.

[26] Viana B.C., Ferreira O.P., Filho A.G.S., HiDalgo A.A., Filho J.M., Alves O.L., Vib. Spectrosc., 55 (2011), 183.
[27] Murashkevich A.N., Lavitskaya A.S., BaranNIKOVA T.I., ZharskiI I.M., J. Appl. Spectrosc., 75 (2008), 730.

[28] Djaoued Y., Badilescu S., Ashrit P.V., BERSANi D., LotTICI P.P., Robichaud J.,J. Sol-Gel Sci. Technol., 24 (2002), 255.

[29] Kim I., Kumta P.N., Mat. Sci.Eng. B, 98 (2003), 123.

[30] Schneider J., Matsuoka M., Takeuchi M., Zhang J., Horiuchi Y., ANPo M., Bahnemann D.W., Chem. Rev., 114 (2014), 9919.

[31] Zhang K.X., Wang W., Hou J.L., ZhaO J.H., ZHANG Y., FANG Y.C., Vacuum, 85 (2011), 990.

[32] Kuscer D., Kovac J., Kosec M., Andriesen R., J. Eur. Ceram. Soc., 28 (2008), 577.

Received 2018-01-25

Accepted 2019-03-29 